\title{
CONHECIMENTO NA SOCIEDADE DA INFORMAÇÃO: CONTRADIÇÕES E APROXIMAÇÕES
}

\section{CONOCIMIENTO EN LA SOCIEDAD DE LA INFORMACIÓN: CONTRADICIONES Y APROXIMACIONES}

\author{
Cristiane Alberto Ferreira Gonçalves cristianealberto@hotmail.com \\ Bibliotecária da Biblioteca Central da UNICAP \\ Aluna do Curso de Especialização em Gestão e Tecnologia da Informação, do Departamento de \\ Ciência da Informação da Universidade Federal de Pernambuco \\ Maria Cristina Guimarães Oliveira macol@ufpe.br \\ Doutora em Serviço Social pela Universidade Federal de Pernambuco \\ Professora Adjunta do Departamento de Ciência da Informação da Universidade Federal de \\ Pernambuco e da Universidade Católica de Pernambuco
}

\begin{abstract}
Resumo
O artigo destaca o valor do conhecimento no contexto da Sociedade da Informação e relata suas bases históricas. Estabelece um comparativo entre os processos produtivos no período da Revolução Industrial e na Era da Informação. Propõe reflexões sobre o domínio do conhecimento comunicado e sua comercialização enquanto bem imaterial. Aborda as tecnologias de informação e comunicação enquanto ferramentas sujeitas à manipulação da vontade política de grupos dominantes e o seu papel de democratizar ou restringir o acesso e uso da informação.
\end{abstract}

\section{Palavras-chave}

Sociedade da informação; Economia da informação; Privatização da informação.

\section{INTRODUÇÃO}

A ideia que a produção, disseminação e apropriação do conhecimento desempenham, juntamente com a informação, um papel central na sociedade da informação é o ponto de partida deste estudo. Considera-se a discussão sobre cada uma dessas potencialidades muito relevante; isto porque a análise da relação entre desenvolvimento eco- 
nômico capitalista, conhecimento, sustentabilidade social e natural, nas últimas décadas, indica enormes contradições, tanto em termos da diferença entre o discurso e a prática do Estado, quanto em relação à própria ação dos vários atores sociais envolvidos, como discute Baumgarten (2008).

É possível perceber que, como materialidade ou como possibilidade de construção, a informação - presente na discussão do social - pede uma interpretação da realidade, do contexto social, antes de ser analisada como categoria. Trata-se de um posicionamento político, no qual não se concebe a informação como um campo isolado e sim, que deve estar vinculada à vida e aos conflitos presentes na realidade contemporânea. Isso fica claro quando se debate ainda mais a relação entre produção/acumulação/distribuição de renda, de um lado; e produção/acumulação/distribuição de conhecimento de outro, levando à necessidade de se repensar a relação entre economia, política e educação científica, como ilustra Maciel (2005).

Nesta perspectiva, concorda-se com Oliveira (2007) que defende o paradigma social da Ciência da Informação e esclarece que só tem sentido falar de uma informação como conhecimento, quando se estabelece uma relação diante de um pressuposto conhecido e compartilhado com outros. Neste caso, o trabalho informativo contextualiza, ou recontextualiza o conhecimento, no qual o valor da informação encontra-se na possibilidade prática de aplicar esse conhecimento às necessidades concretas, além de repensar a forma de articulação e o compromisso de todos com a sociedade. O que, por sua vez, vai ao encontro do pacto ético-político das Ciências Sociais e nesse compromisso, se reforça a responsabilidade de autorizar que o conhecimento construído sirva de suporte às determinações políticas e a compreensão de sua própria realidade.

É sempre interessante lembrar que a discussão sobre o acesso ao conhecimento envolve diferentes abordagens: ação, identidade e liberdade em aspectos distintos. Inicialmente, a produção e a distribuição do conhecimento científico dependem de agentes informados cujo conhecimento, na maioria das vezes está voltado para o desenvolvimento de seus próprios países. O controle sobre essa produção científica e tecnológica se organiza, portanto, mediante as identidades políticas e mercadológicas. Outro ponto diz respeito à instabilidade sistêmica e empiricamente comprovada dos mercados, causada por aquilo que Castells (2003) chama de turbulência da informação. Isto é, informações imperfeitas, surgidas de diversas fontes, que ao proliferarem na rede geram avaliações incorretas; isto é a supervalorização ou subestimação de diferentes empresas públicas ou privadas, marcando a desigualdade material. 
Para Tilly (2006) até bem pouco tempo atrás, os meios coercitivos: trabalho, animais, terra e instituições predominaram na produção mundial da desigualdade. Entre o século XVIII e o passado recente é possível se observar o controle sobre as máquinas, contribuindo para a ampliação da base da desigualdade. Para o autor, surgiram novos focos de recursos geradores de valor no horizonte que contribuem para o entendimento dessa mudança na evolução mundial das máquinas. O primeiro é o capital financeiro cuja volatilidade e quantidade pode conferir vasto poder aos que o controlam, essa característica tem sido bastante discutida no senso comum ao se exemplificar os efeitos do deslocamento de investimentos de um local para outro. Quanto ao segundo tipo de valor, o autor aponta para:

A informação associada à expansão da comunicação eletrônica. Apesar da promiscuidade da internet, a informação é mais fácil de ser reservada do que o dinheiro, as máquinas ou a terra - tudo que exige para isso são apenas circuitos e memórias seguras. [...] O terceiro tipo de valor, meios para armazenamento e transmissão de capital, informação e conhecimento técnico-científico, exerce uma influência parcialmente independente na desigualdade (TILLY, 2006, p. 55).

Para o autor, o quarto tipo refere-se ao conhecimento técnico-científico e assume na atualidade uma importância primordial. Graças ao desenvolvimento da indústria farmacêutica, da engenharia genética, da computação biomecânica, da microeletrônica, dos métodos de diagnóstico médico, das telecomunicações, do mapeamento geofísico e da exploração astrofísica, a inovação científica gera possibilidade de controle e, portanto, de desigualdade sem precedentes.

Entender como é significativa a possibilidade de contribuir para esse debate contém a certeza de que garantias individuais não podem existir sem uma liberdade econômica. Nesse reconhecimento está consignado o papel da informação e do conhecimento à realidade, ao contexto social; notadamente para assegurar o direito que todos devem ter de buscar e levar informações, em todos os lugares que possam ser encontradas.

\section{CIÊNCIA, TECNOLOGIA E INFORMAÇÃO: FORÇAS PRODUTIVAS PARA O DESENVOLVIMENTO}

A revolução trazida pelas tecnologias de informação e comunicação (TICs) observada nas últimas décadas vem transformando a sociedade na sua maneira de ser e agir. As novas tecnologias possibilitam diminuir distâncias, aperfeiçoar custos e modificar de forma 
substancial relações culturais, sociais e econômicas, permitindo uma conexão entre os povos sem precedentes na história da humanidade.

Chamo-a de [Sociedade] informacional, global e em rede para identificar suas características fundamentais, diferenciadas e enfatizar sua interligação. É informacional porque a produtividade e a competitividade de unidades ou agentes nessa economia (sejam empresas, regiões ou nações) dependem basicamente de sua capacidade de gerar, processar e aplicar de forma eficiente a informação baseada em conhecimentos. É global porque as principais atividades produtivas, o consumo e a circulação assim como seus componentes (capital, trabalho, matéria prima, administração, informação, tecnologia e mercados) estão organizados em escala global, diretamente ou mediante uma rede de conexões entre agentes econômicos. É rede porque nas novas condições históricas, a produtividade é gerada, e a concorrência é feita em uma rede global de interação entre redes empresariais. Essa nova economia surgiu (...) porque a revolução da tecnologia da informação forneceu a base material indispensável para sua criação. É a conexão histórica entre a base de informações/conhecimentos da economia, seu alcance global, sua forma de organização em rede e a revolucionária tecnologia da informação que cria um novo sistema econômico (CASTELLS, 2002, p. 50).

Com efeito, podemos destacar como característica fundamental dessa nova sociedade o valor imaterial da informação. Não informação como unidade mínima em um sistema digital - bits circulando nas redes, mas informação enquanto conhecimento comunicado capaz de gerar outros conhecimentos e tornar o indivíduo apto para analisar e identificar oportunidades nessa nova era. Sendo assim, o poder apoiado predominantemente em referenciais de caráter físico não encontra sustentação no contexto atual. Nos dias atuais, o poder está fortemente representado por bens imateriais como a informação.

A história da vida, como a vejo, é uma série de situações estáveis, pontuadas em intervalos raros por eventos importantes que ocorrem com grande rapidez e ajudam a estabelecer a próxima era estável (...) no final do século $X X$ vivemos um desses raros intervalos na história. Um intervalo cuja característica é a transformação de nossa "cultura material" pelos mecanismos de um novo paradigma tecnológico que se organiza em torno da tecnologia da informação (CASTELLS, 2002, p. $67)$.

E é nesse contexto que se relaciona a informação ao poder. Considera-se que para se operacionalizar o poder é oportuno também, a apropriação da informação; porque só o conhecimento é capaz de mudar o destino de economias, gerar poder militar e direcionar medidas estratégicas para concretizar o desenvolvimento social nas diferentes culturas. Assim, vale pensar os processos de comunicação e informação, a partir da cultura. O que denota deixar de pensá-los apenas como meios, e romper com a segurança proporcionada pela redução da problemática à tecnologia, desenvolvendo-se a capacidade de com- 
preender que o funcionamento do aparato tecnológico, que está sendo preparado com a reconversão, depende em larga medida de uma reconversão paralela da utilização social da cultura, como deixa muito evidente Martín-Barbero (1995).

Também Dantas (1996) ilustra esse pensamento e alerta para a ingenuidade de se admitir que as antigas relações de dominação e dependência desapareceram. Para o autor, as grandes potências mundiais complementam força física com sofisticados sistemas de informação, os quais reforçam as disparidades entre elas e as nações menos desenvolvidas. Impotentes, essas nações menos desenvolvidas são lançadas em uma espiral geradora de subinformações, como vem sendo presenciado no cotidiano.

De modo inclusivo, Rojas (2007) chama a atenção para a necessidade de se considerar que a sociedade da informação não é qualitativamente distinta da sociedade capitalista. Para o autor trata-se de apenas mais uma etapa do processo de desenvolvimento e fica evidenciado nessa sociedade que os processos de produção, distribuição, circulação e consumo de bens materiais têm como base as relações mercantilistas, cujos fundamentos encontram-se no princípio da propriedade privada sobre os meios de produção. Isso ocorre de tal maneira que as leis do mercado regulam o processo de produção, o que por sua vez condiciona a estrutura política existente; assim como a divisão social e econômica privada sobre os meios de produção. Deste modo, está comprovada a impossibilidade de se estabelecer uma equivalência entre sociedade da informação e sociedade democrática, justa e igualitária.

Tal como se apresenta é possível se por em questão justamente todo o arcabouço político e jurídico, tão caro à área da informação (mecânica, tecnológica e virtual) que se testemunha ser montado nos dias que correm. Esse arcabouço visa reduzir a informação a um recurso apreciável apenas pelo capital, dela se fazendo instrumento de poder e, concomitantemente, de pouco exercício social, como evidencia Dantas (1996). Nessa lógica, também as profissões são influenciadas na contemporaneidade pelas transformações societárias. O problema teórico-analítico de fundo, posto pelo fenômeno dessas transformações, reside em explicar e compreender como, nas práticas de cada profissão, traduz-se o impacto das transformações societárias. Aí está, então, um dos problemas do campo da Ciência da Informação: essas transformações trouxeram uma grande eficiência mecanicista à área. Mas, por outro lado, não implica necessariamente, em avanço tecnológico e incorporação de tecnologias cada vez mais eficientes. Para Oliveira (2007) o Programa de Desenvolvimento da Educação, na polêmica gestão do Ministro Paulo Renato, na administração do Presidente Fernando Henrique Cardoso (1995-2002) é um arquétipo 
de como se estacionou programas em nome de uma eficiência tecnológica. O Programa de Inclusão Digital, por exemplo, é um dos resultados do programa Sociedade da Informação. Através das discussões em torno dessa sociedade, o Governo FHC tentou implantar o FUST. ${ }^{1}$

A discussão em torno da Sociedade da Informação envolve setores antagônicos e sempre carrega muita polêmica. Caberia mencionar, como ilustração, que o programa Sociedade da Informação, lançado em 1999 pelo Ministério da Ciência e Tecnologia, foi concebido para preparar a nova geração de redes, viabilizando um novo estágio de evolução da internet e suas aplicações no país. O programa nomeia entre seus objetivos, articular, coordenar, fomentar o desenvolvimento e utilização segura de serviços avançados de computação, comunicação, informação e suas aplicações na sociedade. Trata-se de uma política pública de informação, após um longo período sem diretrizes. Isso porque, diante de uma crise que parece que não tem data para terminar, o próprio Estado ignora-a, e acima da sociedade, desenvolve um programa voltado para uma parte dessa sociedade - a menos produtiva, evidentemente, sem buscar alternativas para a autoconsciência social e assim favorecer a democratização do conhecimento. Esse posicionamento governamental é predatório, pois, se aos olhos do primeiro mundo os padrões de eficiência "tecnológica" não são atingidos; internamente, um modelo de informatização de parte da sociedade, justamente a menos preparada para tal, não irá solucionar a disparidade educacional, cultural e tecnológica.

Sobre o assunto, Albagli (2007) comparece ao debate para salientar a clara distinção que deve ser feita entre acesso à informação, acesso à tecnologia e acesso ao conhecimento. $\mathrm{O}$ acesso à tecnologia tem dominado a agenda política sob o apelo de proporcionar a inclusão digital, mas é preciso questionar até que ponto o acesso a equipamentos de informática viabiliza maior acesso a informações e conhecimentos. Cabe ainda mencionar que, entre os trabalhos em andamento no Portal da Sociedade da Informação, encontram-se abordagens diversificadas sobre os vários enfoques que o assunto compreende; entre elas, as avaliações da primeira fase da Cúpula Mundial sobre a Sociedade

\footnotetext{
${ }^{1}$ O Fundo de Universalização dos Serviços de Telecomunicações - FUST foi lançado no governo do Presidente Fernando Henrique Cardoso, no dia 19/02/2001. Tinha como perspectiva a instalação de 250 mil computadores com acesso à internet em 12.500 escolas públicas de ensino médio do país. O programa deveria ser mantido com investimentos inicias da ordem de $R \$ 500$ milhões, provenientes do Fundo de Universalização dos Serviços de Telecomunicações - FUST. Nessa perspectiva, o governo poderia se redimir das disparidades tecnológicas e admitir, que, via "tecnologia" os problemas da educação nacional estariam resolvidos. A qualidade dos computadores colocados à disposição das escolas, a falta de preparo de professores e técnicos de escolas públicas para o uso da tecnologia nunca foi considerada. Mesmo assim, ou apesar disso, o FUST foi um fracasso. Atualmente, não existem registros que acompanhem o desenrolar da novela FUST.
} 
da Informação, realizada em dezembro de 2003, em Genebra. Na ocasião, três pontos de divergência nas negociações multilaterais ficaram evidenciados: o Fundo da Solidariedade Digital; Privacidade e liberdade na rede; Gestão da Internet.

A propósito é interessante observar que os documentos finais não conseguiram dissimular o fracasso de todos esses pontos, porque os paises ricos negam-se a aceitar e manter compromissos financeiros que viabilizem a criação de um fundo de solidariedade digital.

Sociedade da Informação, Global Information Society, em seu nome de origem conceitual e lingüística, Sociedade do Conhecimento, Nova Economia, são expressões geradas no interior do mesmo fenômeno e que, se não recobrem exatamente os mesmos significados, pertencem, contudo, ao mesmo campo semântico estendido na planura da retórica redencionista da globalização. Nesse sentido, o Brasil, antes mesmo da apropriação da materialidade abstrata da globalização, que é a livre circulação do capital financeiro, foi se apropriando, pelos projetos e programas que constituem os marcos das aspirações da sociedade mundializada, dessa retórica-simulacro-de-inclusão (VOGT, 2001, p.1).

Na segunda fase de reuniões em 2005, a Cúpula Mundial sobre a Sociedade da Informação não tratou de maneira decisiva e concreta a questão do financiamento para projetos de tecnologias da informação e comunicação na América Latina e no Caribe. Contudo, um avanço importante teve lugar: o início das negociações de um plano de ação regional para a América Latina e Caribe. Assim, o Grupo de países da América Latina e Caribe está para decidir as linhas gerais de um mecanismo regional a ser coordenado por representantes dos governos do Equador, Brasil, El Salvador e de um país da comunidade Caribenha. Fica evidente um recorte regional e, sobretudo, a discussão através do Fórum de Governança da Internet.

Em andamento, na reunião realizada em janeiro de 2007, ficou decidido que o Projeto da Sociedade da Informação no MERCOSUL será coordenado pela Rede Nacional de Ensino e Pesquisa - RNP, que também será executora e responsável pelo acompanhamento do projeto de desenvolvimento da sociedade e pela criação de uma rede de cooperação entre os países do MERCOSUL. Especialmente é possível se identificar no Plano de Ação do MCT as inovações e os investimentos que o governo e o setor empresarial dedicam à ciência e à tecnologia. Países como o Brasil necessitam de investimentos em C\&T e setores estrategicamente selecionados, sem esquecer a livre criação de conhecimento, responsável pela produção de tecnologia. De tal modo, a pesquisa em áreas situadas na chamada fronteira do conhecimento deve ser uma das grandes prioridades da 
ação governamental, por meio do fomento direto a instituições de pesquisa e do estímulo ao envolvimento do setor empresarial.

Mesmo assim, com propriedade Baumgarten (2008) discute o papel que a ciência e a tecnologia sempre desempenharam como força produtiva e dão lugar, na atualidade a tecnociência "um sistema de ações eficientes baseadas em conhecimento científico" (BAUMGARTEN, 2008, p. 103). Mas, é preciso se repensar as relações em pauta na sociedade entre ciência, tecnologia e sustentabilidade. Isto porque, a sociedade brasileira e seus alarmantes índices de desigualdade não nos permitem generalizações nem admitir que exista uma participação integral numa Sociedade da Informação.

Ao lado desta Sociedade da Informação, há sem dúvida uma outra - a Sociedade da Desinformação - que pouco é retratada, porque aquela esconde esta, ou esta não é objeto de desejo da Ciência da Informação. Ao tratarmos da primeira, sem desviarmos o olhar para a "outra" construímos um discurso vazio de sentidos (CASTRO, 1997, p. 20).

Dias (1997) corrobora esse pensamento quando menciona que o mercado parece reinar sozinho, ancorado no maior monopólio de comunicação e tecnologia jamais vistos. Trata-se de um processo acelerado, contínuo e crescente de integração passiva à ordem econômica vigente. Para o autor, não há como negar que:

A imensa potencialidade dos processos produtivos comandados por novas formas de gestão (formas condensadas da política das classes dominantes) articuladoras de possibilidades produtivas que parecem possuir uma capacidade infinita de crescer. Na realidade, a chamada III Revolução Industrial nada mais é do que a submissão atual do trabalho ao capital. O que é inaceitável é introduzir uma forma de determinismo tecnológico, tradução atualizada das vertentes positivistas que aliam liberalismo político, liberalismo econômico e cientificismo (DIAS, 1997, p. 134).

\section{SOCIEDADE DA INFORMAÇÃO: BASE ECONÔMICA E HISTÓRICA}

As mudanças sociais não ocorrem de modo repentino ou ocasional, elas são fruto de uma combinação de fatores, ligados a interesses econômicos, políticos e até religiosos. Nessa perspectiva é possível apontar a Revolução Industrial como a "mãe" da Revolução da Tecnologia da Informação e, por conseguinte, a base da Sociedade da Informação. Iniciou-se no séc.XVIII, na Inglaterra, com a mecanização dos sistemas de produção; fundamentou o conjunto de mudanças tecnológicas e gerou grandes transformações nos processos produtivos, inclusive a economia e o desenvolvimento social da época. A partir do século XIX, a Revolução Industrial expandiu-se pelo mundo, transformando em escala 
mundial a visão de propriedade. Dessa forma, a Inglaterra firmou sua hegemonia nas relações internacionais, difundindo o liberalismo econômico, a acumulação de capital (o capitalismo já era o sistema econômico vigente) e suas inovações tecnológicas nos meios de transportes, tais como o barco e o trem a vapor, conhecido no Brasil como "Maria Fumaça", além de outras invenções como a iluminação de rua.

Nesse caso registra-se que a Revolução Industrial alterou definitivamente o modo de vida das pessoas nos paises industrializados. Um momento histórico marcado pelo êxodo rural, no qual as populações migraram do campo para os centros urbanos em busca de trabalho, porque as cidades industrializadas representavam o progresso, a possibilidade de uma vida melhor, onde seria possível trocar força de trabalho por salário e assim, consumir bens e serviços. Se bem que, ao voltar o olhar para esse passado recente da história da humanidade, se ressalta que as novas técnicas de produção tiveram sua origem em áreas geográficas restritas: Inglaterra, Estados Unidos da América, França, Alemanha e Japão (HOBSBAWM, 2003); regiões onde já havia uma forte concentração de riqueza e desenvolvimento intelectual. Ortega (2004) anota que os trabalhadores desses mencionados países foram capazes de aprender e desempenhar atividades específicas naquele contexto de industrialização, especificamente na Inglaterra e nos Estados Unidos. Assim, o livre-comércio pode ser fortalecido e o capital ora mercantil, tornou-se industrial. O valor do capital não estava associado à posse de terras, mas passa a ter sua referência associada à posse de máquinas e tecnologia.

Dessa forma, a Revolução Industrial na linha histórica da humanidade, foi o marco da evolução tecnológica, econômica e social, que veio se desenvolvendo na Europa desde a Idade Média, predominantemente nos países de origem protestante e que se projetou para o futuro até os dias de hoje. Sucede que o ambiente informacional em outros períodos era diferente, estava apenas implícito e nem sempre percebido igualitariamente. As condições que determinaram o aparecimento de uma sociedade basicamente ligada à informação são todas interconectadas, o que as torna, por sua vez influenciadas dialeticamente pela globalização, tecnologia, mercado, relações de troca entre países e pelo próprio funcionamento dessa sociedade.

Considera-se que o potencial do desenvolvimento local se expressa como um novo referencial de crescimento. Experiências têm sido analisadas não apenas pelo impacto econômico local, mas como portadores de profundos questionamentos junto aos sistemas tradicionais de produção, de crédito, de organização social e de mercado. A globalização vem impondo novos padrões de concorrência às empresas, que, para se manterem com- 
petitivas no mercado precisam redefinir suas estratégias e elevar a produtividade através, principalmente, da adoção de novos métodos de organização do trabalho, aumento da escala de produção, ampliação do número de produtos comercializados e crescimento da indústria. Não se perde de vista que as fontes indutoras de inovação vêm se constituindo através da articulação empresarial com o sistema científico, técnico e de pesquisas locais, nos quais está presente a informação como fluxo dinâmico e estratégico para o desenvolvimento, esclarece Magalhães (2000).

Não se perde de vista que a necessidade de promover o desenvolvimento do aparato produtivo visa especialmente reduzir a vulnerabilidade local a ofertas de equipamentos importados e de outros setores difusores do progresso técnico, ou seja, enfraquecer a dependência tecnológica. Mesmo assim, o entrave à adoção de inovações no país tem sido objeto de diversas abordagens.

Dagnino e Novaes (2007) discutindo a limitação do empresariado brasileiro quanto à inovação e ao desenvolvimento econômico nacional trazem uma pertinente observação, segundo a qual é possível se intuir na direção da superestrutura, o resultado que a postura subordinada ao capital internacional do nosso empresariado determinara em termos político-ideológicos; a ameaça que isso representava para a democracia e a importância que teve para a conformação do estado latinoamericano:

Trata-se de uma concentração da riqueza e da renda muito maior do que a vigente nos países de capitalismo avançado, o que gerou um ambiente político que engendrou, com a intermediação do Estado, a elaboração de políticas públicas capazes de proporcionar no nível da infraestrutura econômico-produtiva um mecanismo de apropriação do excedente que, ao contrário do que ocorre no capitalismo tout court, não se apóia no progresso tecnológico. Teria sido um mecanismo de inflação-reajuste regulado pelo Estado e pelo mercado, cuja melhor denominação talvez seja mecanismo de inflação-reajustedisciplnamento (ou mecanismo inflacionário/repressivo) o que possibilitou a implementação de políticas econômicas e sociais concentradoras que levaram a uma deterioração contínua do salário real e assim, à instauração de uma forma de extração da mais-valia que prescinde da introdução do conhecimento na produção. A existência de uma anômala concentração de poder político e econômico teria facultado às elites brasileiras uma verdadeira inovação: instaurar um tipo de capitalismo (periférico) cuja reprodução não está baseada na extração de mais valia (DAGANINO; NOVAES, 2007, p. 10). 


\subsection{Consumo da Informação}

A sociedade moderna está absolutamente arraigada à informação e a exemplo da Revolução Industrial, a revolução das tecnologias de informação também transforma a paisagem econômica e social do mundo moderno. Podemos comparar os ambientes digitais às cidades industrializadas, lugar onde o futuro acontece e se ampliam os fluxos de troca em todos os sentidos, econômicos, sociais e políticos, consequentemente as possibilidades de desenvolvimento são inimagináveis. Sobre o assunto, Albagli (2007) comenta as mudanças em atuação na sociedade e menciona a passagem de um regime de informação estado-cêntrico focado no conhecimento de caráter público, para um regime centrado no mercado. Contudo, para que o progresso seja uma realidade é essencial obter a informação e o conhecimento, sem os quais os processos produtivos ficam comprometidos. "A fonte de produtividade e crescimento reside na geração de conhecimento, estendido a todas as esferas da atividade econômica mediante o processamento da informação" (CASTELLS, 2002, p. 267).

Historicamente o conhecimento sempre foi fonte de poder, entretanto na Sociedade da Informação ele se torna um bem comercializável. Conforme Lorenzetti (2004), para que a informação registrada adquira um caráter de bem comercial e a ela seja concedido direitos de propriedade, é absolutamente necessário que ela seja privada. Assim, no contexto da economia, a informação registrada deixa de ser um instrumento e passa a ser um bem em si mesmo. Isto porque, Anteriormente, a forma de acúmulo de capital era basicamente realizada através da comercialização de bens tangíveis produzidos a partir de recursos não-renováveis. As novas tecnologias de informação e comunicação transformaram esse cenário e tornam possível materializar o que é em sua essência imaterial, a informação e o conhecimento, através das inovações para sua codificação, decodificação, armazenamento, disseminação e recuperação.

Ao contrário do que ocorre com os bens materiais, o consumo de informação e conhecimento não os destrói, assim como seu descarte geralmente não deixa vestígios materiais. Cedê-los ou vendê-los não faz com que sejam perdidos. Nessa área prevalece, portanto, uma abundância natural (LASTRES; CASSIOLATO, 2006, p. 3).

E esta abundância natural já foi identificada e reconhecida pelos países mais avançados do mundo, de onde provêm as iniciativas de controle, e mercantilização da informação. As bases de dados internacionais, com centenas de periódicos internacionais e milhares de informações hábeis para a geração de conhecimento são apenas um exemplo da nova maneira de se acumular capital no contexto social atual. 
As significativas conseqüências geopolíticas das referidas transformações não podem ser ignoradas. (...) a apropriação de conhecimentos e informações possui especificidades que não podem ser ignoradas, pois são recursos intangíveis que podem ser usados - inclusive simultaneamente - por várias pessoas sem problemas de esgotamento (LASTRES; CASSIOLATO, 2006, p. 5).

A característica intangível da informação e do conhecimento aliada as TICs constituem uma possibilidade real de democracia e de desenvolvimento; todavia não tem sido sempre assim, pois cada vez mais são utilizadas como instrumento para acúmulo de capital e poder. O novo modo de acumulação do capital contém a intensidade e complexidade dos conhecimentos desenvolvidos e sua acelerada incorporação aos bens e serviços produzidos e comercializados. Para Lastres e Cassiolato (2006) especialmente as tecnologias da informação e informação exercem papel central no dinamismo do novo padrão de acumulação, alavancando um conjunto de inovações técnico-científicas e sociais.

A informação registrada como um bem comercializável é indispensável para a produtividade, diante disso, o conhecimento comunicado torna-se o fator mais importante na competição mundial pelo poder. Como acompanhamos na Revolução Industrial, o trem e o barco a vapor viabilizaram o transporte da matéria-prima e dos produtos já industrializados, promovendo o desenvolvimento e a manutenção do poder dos países ricos. Da mesma forma, a revolução da tecnologia da informação criou mecanismos, como a Internet e um sem número de softwares e hardwares capazes de transportar o elemento essencial para o desenvolvimento da Sociedade da Informação: o conhecimento. Neste contexto, observamos que as TICs tornam-se a plataforma para a legitimação do poder de atores econômicos mundiais.

$\mathrm{Na}$ sociedade moderna, em que há um condicionamento social para a crença nos valores democráticos e da livre iniciativa, sobram casos de manipulação do "mercado" e de influências políticas por parte de grandes empresas (SILVEIRA, 2000, p. 79).

Se os avanços gerados pelos processos de produção, transmissão e uso do conhecimento, pouco tem contribuído para alterar a sistemática do poder no mundo, por sua vez, paralelamente a liberdade de escolha existe, se incrementa a concentração, e a diferença de poder é cada vez mais notória. Conforme Lorenzetti (2004), a padronização é vantajosa e necessária, mas assenta uma base para que os grandes grupos estabeleçam monopólios em matéria de software, hardware e comunicações.

Para Lévy (2000) o ciberespaço acelera a virtualização geral da economia e da sociedade, porque estamos diante de um oceano de informações, um mundo novo cheio de 
possibilidades para o desenvolvimento humano. Contudo, a liberdade e descentralização do ciberespaço, não eliminam necessariamente, os núcleos de controle dos recursos, das competências e dos mercados onde quer que eles estejam.

Já Sánches Gamboa (1997) contrapõe-se ao pensamento de Lévy afirmando que informações utilizadas nos processos produtivos, na tomada de decisão e na geração de novas tecnologias são rigorosamente controladas. No entanto, outras informações que geram dispersão, diversão, entretenimento ou veiculam ideologias e concepções fantasiosas são dispostas sem nenhum controle. O que gera uma sociedade de consumidores de informação sem exigências ou critérios significantes para uso de informações. As opiniões divergentes evidenciam os diferentes posicionamentos políticos que envolvem o assunto e que, efetivamente enriquecem o debate, mas não são conclusivas.

\section{CONSIDERAÇÕES FINAIS}

O tema é demasiadamente complexo e abordado sob diferentes aspectos na literatura consultada; entretanto, nesse ensaio sobre o valor do conhecimento na Sociedade da Informação, objetivou-se apontar as TICs como a base material para estabelecer os processos imateriais de acúmulo de riquezas e poder na era da informação. Paralelamente, foi possível ressaltar o impasse entre o fantástico avanço das tecnologias de informação e sua aplicabilidade para ampliação ou redução dos processos democráticos de disseminação e uso do conhecimento comunicado. A partir dos quais o desenvolvimento social e econômico nas diferentes sociedades poderá ocorrer de modo mais igualitário, considerando-se que os resultados devem ser aplicados para a conquista de mudanças.

$O$ acesso desigual ao conhecimento científico e o controle irregular sobre a produção e distribuição desse conhecimento são temas importantes cuja discussão não se esgota aqui; isto porque o debate é relevante não apenas pelo valor intrínseco da informação e do conhecimento, mas sobretudo pela consciência que sua distribuição desigual gera concentração de poder, mais desigualdade e confere vantagens políticas e financeiras aos que o detêm. É possível se afirmar que a tecnologia que liberta e alarga os horizontes do homem, é a mesma que o aprisiona e excluí, pois o seu uso, ainda é predominantemente determinado pela vontade política de grupos dominantes.

O problema encontra-se exatamente aí - toda essa tecnologia, seus diferentes e diversificados procedimentos de acesso favoreceu a ampliação da distância entre os que podem ter acesso a informação e os que não podem, por diferentes razões. Assim, mes- 
mo correndo o risco de reproduzir uma expressão já desgastada pelo senso comum, concorda-se que existe um espaço entre os incluídos e os excluídos tecnológicos. O debate entre inclusão e exclusão tecnológica não tem fim e, obviamente, envolve inúmeras conotações políticas e principalmente econômicas. É possível, entretanto, adiantar com segurança, que não é o acesso aos computadores, tão largamente apregoado pelos governantes, que caracteriza uma inclusão digital. Muito pelo contrário, a inclusão se dá através da educação e da consciência crítica, pois se considera que do ponto de vista do avanço do conhecimento, sua apropriação social é que vai caracterizar o desenvolvimento em toda sua extensão.

\section{REFERÊNCIAS}

ALBAGLI, S. Sociedade da informação e do conhecimento: desafios teóricos e empíricos. Liinc em Revista, Rio de Janeiro, v.3, p.10-16, 2007.

BAUMGARTEN, M. Ciência, tecnologia e desenvolvimento: redes de inovação social. Parcerias Estratégicas, Brasília, DF, v. 26, p.101-118, 2008.

CASTELLS, M. A sociedade em rede. 6. ed. rev. ampl. São Paulo: Paz e Terra, 2002. v. 1.

CASTRO, C.A. Sociedade da informação: dilema para o bibliotecário. Transinformação, São Paulo, v.9, n.1, p-17-25, jan./abr., 1997.

DAGNINO, R.; NOVAES, H. T. Por que os "nossos" empresários não inovam? In: SEMINÁRIO DE MODERNIZAÇÃO PERIFÉRICA, X ., 2007, Recife, Anais eletrônicos. Recife, FUNDAJ, 2007.

DANTAS, M. Valor-trabalho e valor-informação. Transinformação, Campinas, v. 8, n.1, p. 55-88, jan./.abr., 1996.

DIAS, E. F. A liberdade (im)possível na ordem do capital: reestruturação produtiva e passivização. Campinas: UNICAMP/IFCH, 1997.

HOBSBAWM, E. J. Da revolução industrial inglesa ao imperialismo. 5. ed. Rio de Janeiro: Forense Universitária, 2003.

LASTRES, H. M. M.; CASSIOLATO, J. E. Inovação, informação e conhecimentos: a importância de distinguir o modo da moda. DataGramaZero: revista de ciência da informação, v. 7, n. 1, fev. 2006. Disponível em: < http://www.dgz.org.br/fev06/ Art_01.htm >. Acesso em: 29 mar. 2009.

LÉVY, P. Cibercultura. 2. ed. São Paulo: Ed. 34, 2000.

LORENZETTI, R. L. Comércio eletrônico. São Paulo: Revista dos Tribunais, 2004.

MACIEL, M. L. Ciência, tecnologia e inovação: idéias sobre o papel das ciências sociais no desenvolvimento. Parcerias Estratégicas, n. 21, dez. 2005. 
MAGALHÃES, R. S. A nova economia do desenvolvimento local. In: CONFERÊNCIA DA WORK AND LABOUR NETWORD, 2., 2000, Rio de Janeiro. Anais... Rio de Janeiro, 2000.

MARTÍN-BARBERO, J. América Latina e os anos recentes: o estudo da recepção em comunicação social. In: SOUZA, Mauro W. (Org.). Sujeito, o lado oculto do receptor. São Paulo: Brasiliense, 1995.

OLIVEIRA, M. C. G. O uso social da informação na Rede de Desenvolvimento de Santo Amaro, 2007. 146 f. Tese (Doutorado em Serviço Social)- Universidade Federal de Pernambuco, Recife, 2007.

ORTEGA, C. D. Relações históricas entre biblioteconomia, documentação e ciência da informação. DataGramaZero: revista de ciência da informação, v. 5, n. 5, out. 2004. Disponível em: <http://www.dgz.org.br/out04/F_I_art.htm>. Acesso em: 12 mar. 2009.

ROJAS, M. A. R. Los valores sociales y políticos dentro del paradigma bibliotecologico en la era de la información. Transinformação, Campinas, v. 19, n. 1, p. 9-18, jan./abr. 2007.

SÁNCHEZ GAMBOA, S. Revolução informacional : pontos de vista para o debate sobre a sociedade da informação. Transinformação, Campinas, v. 9, n. 1, p. 32-42, jan./abr. 1997.

SILVEIRA, H. F. R. Um estudo do poder na sociedade da informação. Ciência da Informação, Brasília, DF, v. 29, n. 3, p. 79-90, set./dez. 2000.

TILLY, C. O. O acesso desigual ao conhecimento científico. Tempo Social: revista de sociologia da USP, São Paulo, v.18, n. 2, p. 47-63, nov. 2006.

VOGT, C. Informação e simulacro. Disponível em: <http://www.comciencia.br/ reportagens/socinfo/rtf/infotudo.rtf>. Acesso em: 15 fev. 2009.

\section{Titulo}

Conocimiento en la sociedad de la información: contradiciones y aproximaciones

\section{Resúmen}

El artículo destaca el valor del conocimiento en el contexto de la Sociedad de la Información y relata sus bases históricas. Establece un comparativo entre los procesos productivos en el periodo de la Revolución Industrial y en la Era de la Información. Propone reflexiones sobre el dominio del conocimiento comunicado y su comercialización mientras bien inmaterial. Aborda las tecnologías de información y comunicación mientras herramientas sujetas a la manipulación de la ganancia política de grupos dominantes y el papel de democratizar o restringir el acceso y uso de la información.

\section{Palabras clave}

Sociedad de la información. Economía de la información. Privatización de la información. 
Recebido em: 01.05.2009

Aceito em: 09.06.2009 